\title{
Analysis of Solar District Cooling systems: the Effect of Heat Rejection
}

\author{
Giovanni Brumana ${ }^{1 *}$, Giuseppe Franchini ${ }^{1}$, Elisa Ghirardi ${ }^{1}$ and Antonio Perdichizzi ${ }^{1}$ \\ ${ }^{1}$ University of Bergamo, Department of Engineering and Applied Sciences, Viale Marconi 5, Dalmine \\ 24044 (BG), Italy
}

\begin{abstract}
The paper presents the performance assessment of a solar district cooling system with special attention to the heat rejection process. The investigation includes energetic, economic and environmental aspects. The district cooling network is driven by two-stage $\mathrm{Li}-\mathrm{Br}$ absorption chillers coupled with parabolic trough solar collectors. The whole system, including solar field, storage tanks and chilled water pipeline, has been modelled in Trnsys. The focus is on the heat rejection systems, and their impact on the performance of the cooling plant. Four different types of heat rejection systems are considered: Air Cooling (AC), Evaporative Cooling Tower (ECT), Groundwater Heat Exchanger (GHE) and Geothermal Boreholes (GB). The paper presents two case studies in the Gulf region: the warm climate is compared for two condition of humidity, dry (Riyadh) and humid (Abu Dhabi). Furthermore, the work presents a multivariable optimization procedure based on GenOpt software interacting with Trnsys model under the constraint of a $70 \%$ annual solar fraction. The best option resulted to be the one based on absorption chillers coupled with Groundwater Heat Exchanger in both locations. The annual power consumption is reduced by $83 \%$ in Abu Dhabi and $82 \%$ in Riyadh compared to conventional cooling systems.
\end{abstract}

\section{Introduction}

Worldwide, power consumption for cooling systems is responsible for $10 \%$ of the global electricity usage and $14 \%$ of the peak demand [1]. In order to increase efficiency and sustainability, the scientific community is addressing big efforts to develop centralized cooling technologies driven by renewable sources.

A promising solution is the development of centralized cooling plant with a consistent energy reduction [2] and peak-shaving effect. The adoption of district cooling in the new urbanized area project [3] reduce consistently the emission and improve the sustainability of the residential conditioning especially when coupled with Thermal Energy Storage [4]. However, the complexity of the plant requires a detailed modelling and optimization of the district network in addition to the cooling plant $[5,6]$.

Unfortunately, the ambient condition responsible of the air conditioning request represent a weakness for the cooling system; the high temperature of air limits the chiller operation with heat rejection chiller based on dry cooler and high relative humidity reduce the efficiency of cooling tower. The different heat recovery systems have already been well-analyzed in numerous studies,

*Corresponding author: giovanni.brumana@unibg.it 
as proposed by Eicker et al. [7]. Dry cooler is the most common heat rejection system for residential and industrial applications: in hot climates, air-cooled chillers exhibit a low efficiency due to high ambient air temperature [8,9]. Cooling towers perform well with low wet bulb temperatures, however the requirement of water make-up represent a critical point in countries with water scarcity, such as in the Gulf region.

If available, shallow groundwater or seawater could represent an alternative, since the average temperature is typically lower than air temperature improving the chiller efficiency. McLing et al. [10] demonstrated that the use of groundwater for energy purposes is advantageous where an aquifer is available and the thermal flow is relevant. The possibility of using groundwater for cooling application is related to two main parameters: presence and salinity, as reported in [11]. The presence of brackish water in the subsoil, especially in the UAE region, allow to implement heat rejection systems with water circuit, preserving the freshwater resources. Indeed, fresh water plays an important role in arid regions where water resources depend on rainfall [12] and during the years are always of lower intensity [13], tending to a gradual deterioration of the reserve. To determine the presence of groundwater a detailed study of the geology of the region needs to be developed and several studies have shown the complexity of the hydrogeology of the Arabian Peninsula [14,15]. The presence of salt in the groundwater, excluding other uses (such as agriculture or farms), benefit the heat rejection application. The salinity is related to seawater intrusion into the coastal aquifer, mainly caused by tides and pumping wells that raise saline wedge. In coastal regions water could be pumped directly from the sea, but to compensate the high temperature of the water surface and the shallow backdrops of the peninsula, it is necessary to use long drainage pipes to draw water at a correct temperature.

The use of geothermal probes as a heat rejection system can be a good alternative to avoid water consumption and keeping the cooling circuit at low temperatures but soil thermal saturation has detrimental impact on plant performance. The use of geothermal probes for air conditioning dates back many years ago and the study of these solutions is developed especially for heating. The possibility to use the geothermal resources of the Arab peninsula was been proposed Salem and Hashim [16].

The work, starting from previous researches [17,18], deal with the design of a district cooling network driven by two-stage $\mathrm{Li}-\mathrm{Br}$ absorption chillers coupled with parabolic trough solar collectors. The impact of heat rejection systems on the performance of the cooling plant is analyzed in detail. Four different types of heat rejection systems are compared: Air Cooling (AC), Evaporative Cooling Tower (ECT), Groundwater Heat Exchanger (GHE) and Geothermal Boreholes (GB).

\section{Models and methods}

The paper proposes a deep evaluation of a complete solar district cooling plant including the heat rejection systems. The solar district cooling system is schematized in Fig. 1. The solar field provide the heat to a central $\mathrm{Li}$-Bi absorption chiller and a pipeline system distribute the chilled water to each building. The cooling load of a residential compound of 48 single villas is accurately predict with an annual transient simulation, including the peak shaving effect, the district thermal inertia and the thermal dissipation across the piping. The whole system, including solar field, storage tanks and chilled water pipeline, has been modelled in Trnsys and the meteo data adopted in the simulations are based on the Meteonorm [19] database. The performance map of the chillers, provided by the manufacturer, are integrated in the physical model thus allowing an accurate simulation both in design and off-design operation. The cooling plants have been optimized for two locations that represent two common operative conditions in hot climates, "hot and dry" with low relative humidity (Riyadh - KSA), and "hot and humid" with a combination of high temperature and high relative humidity due to the sea proximity (Abu Dhabi - UAE). 
The cooling plant model are coupled with four different heat rejection systems, accurately presented in the following paragraphs. Different configurations of the district cooling are compared with the standard solution of distributed cooling generation based on air cooled heat pump.

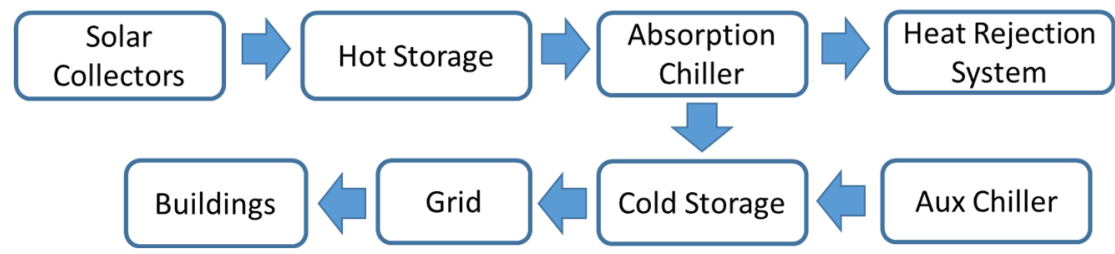

Fig. 1. Schematization of the solar district cooling system

\subsection{Residential compound and District Cooling network}

The residential compound was based on a single villa model, developed in Trnsys 18, analyzed and simulated in [18] using a detailed transient simulation. The two-floor villa represent a common residential building of the MENA region and the specification respect the Dubai Green-Building Regulation and Specification [20]. The result of the building simulation in terms of peak load and annual cooling load are reported in Table 1, for both the conditions considered. It is highlighted that both locations show a similar sensible cooling load, however, the high relative humidity of Abu Dhabi increase the latent load that represent $40 \%$ of the global load.

Table 1. Cooling load a single building (Global - Sensible)

\begin{tabular}{|c|c|c|}
\hline Cooling load & Abu Dhabi & Riyadh \\
\hline Peak cooling load $(\mathrm{kW})$ & $47.33-31.10$ & $30.66-30.61$ \\
\hline Annual cooling load $(\mathrm{GWh})$ & $156.72-97.30$ & $90.41-89.60$ \\
\hline
\end{tabular}

Table 2. District cooling load

\begin{tabular}{|c|c|c|}
\hline Annual cooling load (GWh) & Abu Dhabi & Riyadh \\
\hline Cooling load (building substation) & 7522 & 4340 \\
\hline Cooling load (cooling plant) & 7998 & 4653 \\
\hline Thermal losses (\%) & $6.32 \%$ & $7.21 \%$ \\
\hline
\end{tabular}

The cooling load of the 48 villas in the residential compound was modeled by combining the demand of a single building. The numerical model considers non-contemporaneity of each villas and the effect of the piping as proposed by the authors in [17], including the thermal losses evaluation under real operation conditions and the effect of the heat transfer substation. The design water speed is $2.75 \mathrm{~m} / \mathrm{s}$ and the piping insulation is equal to $5 \mathrm{~cm}$ as reported by the design practice [21]. The results of the district network simulations are listed in Table 2 and the monthly cooling load is shows in Fig. 2. 


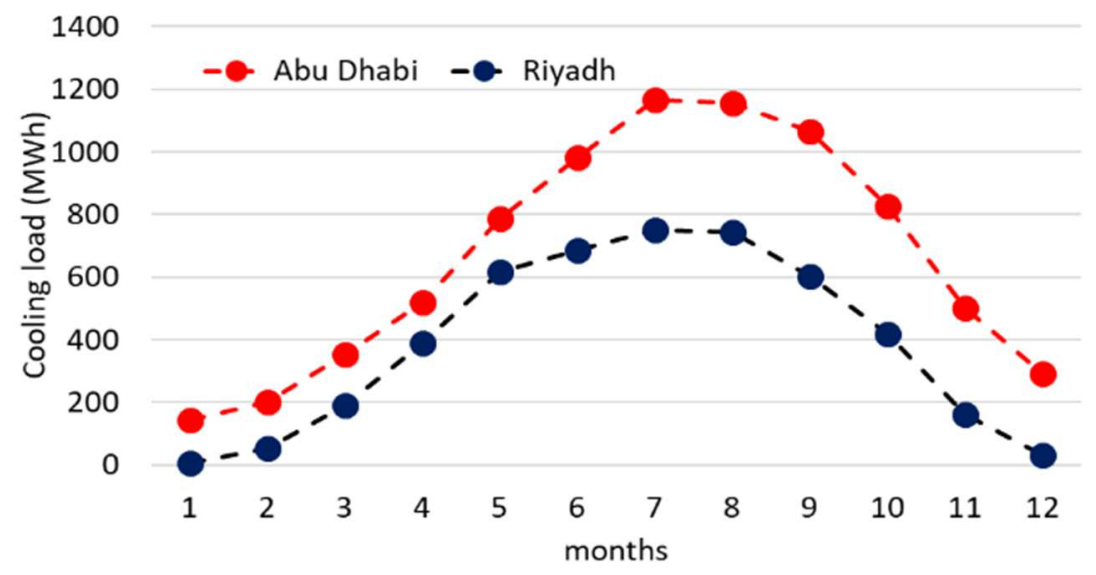

Fig 2. Building monthly cooling load

\subsection{Solar cooling system}

The solar cooling plant was based on the two stage $\mathrm{Li}-\mathrm{Br}$ absorption chiller driven by a parabolic trough solar field that represents the actual best cost-effective solution [18]. The model includes a backup compression chiller to cover the full load. The PTC solar field performance evaluation is based on the eq. (1), where $\bar{T}$ represents the mean temperature between inlet and outlet of the collector, and BTI is the beam total irradiance.

The main solar field operation parameters and the chiller specifications are reported in Tab. 3. The plant includes a two-tank configuration: the hot storage between the solar field and the chiller, the cold storage between the chiller and the pump station with a volume equal to $50 \%$ of the hot one. The adoption of two separated tank for the heat and cold circuits allows to the solar field and to the chiller to operate under design operation most of the time, maximizing the conversion efficiency. The solar field set point temperature is selected according the two-stage absorption chiller input. The solar circuit and hot storage are designed based on pressurized water as 12 bars.

$$
\eta=a_{0}-a_{1} \frac{\bar{T}-T_{a m b}}{B T I \cdot C R}-a_{2} \frac{\left(\bar{T}-T_{a m b}\right)^{2}}{B T I \cdot C R}
$$

Table 3. PTC specifications and 2sAbsorption chiller specifications

\begin{tabular}{|c|c|c|c|c|c|}
\hline \multicolumn{4}{|c|}{ Solar Field $(P T C)$} & \multicolumn{3}{c|}{ 2sABS chiller design performance } \\
\hline Outlet set point temp* & ${ }^{\circ} \mathrm{C}$ & 175 & Rated COP & - & 1.39 \\
\hline Concentration ratio (CR) & - & 60 & Hot source range & ${ }^{\circ} \mathrm{C}$ & $121-175$ \\
\hline Optical efficiency (a0) & - & 0.7719 & Chilled water (in-out) & ${ }^{\circ} \mathrm{C}$ & $12-7$ \\
\hline $1^{\text {st }}$ order heat loss coeff. $\left(\mathrm{a}_{1}\right)$ & $\mathrm{W} / \mathrm{m}^{2} / \mathrm{K}$ & 0.1803 & Hot water (in-out) & ${ }^{\circ} \mathrm{C}$ & $175-155$ \\
\hline $2^{\text {nd }}$ order heat loss coeff. $\left(\mathrm{a}_{2}\right)$ & $\mathrm{W} / \mathrm{m}^{2} / \mathrm{K}^{2}$ & 0.0258 & Cooling water (in-out) & ${ }^{\circ} \mathrm{C}$ & $30-35$ \\
\hline
\end{tabular}

The absorption chiller nominal capacity is fixed and selected equal to $60 \%$ of the peak load; by this way the nominal capacity (in design condition) allows to cover $90 \%$ of the annual cooling load. The operations of the main chiller are simulated using a performance map provided by the manufacturer and detailed reported in [18]. The nominal capacity of the auxiliary compression 
chiller is selected equal to the absorption chiller unit and the main parameters are reported in Table 4 left.

Finally, a detailed model of a single unit heat pump, adopted in the distributed solution, is presented. The heat pump cooling circuit is based on dry cooler unit and the plant work on direct mode, without thermal energy storage. The capacity of the heat pump is selected equal to 1.5 times the peak cooling load to compensate the temperature derating. The heat pump specifications are listed in Table 4 right part.

TABLE 4. Auxiliary compression chiller and Heat Pump design parameters

\begin{tabular}{|c|c|c|c|c|c|}
\hline \multicolumn{3}{|c|}{ Compression Chiller } & \multicolumn{3}{c|}{ Heat Pump } \\
\hline & unit & value & & unit & value \\
\hline Chiller capacity* & $\mathrm{kW}$ & 1000 & Chiller capacity** & $\mathrm{kW}$ & 21.70 \\
\hline COP* $^{*}$ & - & 4.65 & COP** & - & 2.94 \\
\hline Power input* & $\mathrm{kW}$ & 215 & Power input** & $\mathrm{kW}$ & 7.38 \\
\hline
\end{tabular}

* Ambient temperature $35 \mathrm{deg}$. C; chilled water 7-12 deg. C. ** Ambient temperature 30 deg. C; chilled water 7-12 deg. C.

\subsection{Heat Rejection systems}

In the present work, four different heat rejection systems have been considered: dry air cooler, cooling tower, groundwater and geothermal.

Dry coolers are usually preferred for residential installation, and typically coupled with a compression chiller in regions with water resources scarcity. Furthermore, the use of dry coolers in solar cooling applications based on absorption-adsorption chiller is very complicated [22]. In fact, to avoid lithium bromide crystallization problems, the chillers are switched off when the cooling circuit temperature reaches $35 \mathrm{deg}$. $\mathrm{C}$ and with dry coolers is difficult to guarantee this limit temperature. Specifications of the dry cooler adopted in the model are reported in the left part of Table 5 .

Heat rejection circuits based on cooling tower are the current standard for industrial application. Cooling tower shows the best efficient in temperate climates: the low relative humidity and moderate temperature improve the performance. The cooling water provided by cooling tower is supplied at ideal temperatures for absorption chiller operation. Table 5 (right part) resumes a list of technical specifications of the ETC model included in the simulations.

TABLE 5. Dry cooler specification and cooling tower specification

\begin{tabular}{|c|c|c|c|c|c|}
\hline \multicolumn{3}{|c|}{ Dry cooler specifications } & \multicolumn{3}{c|}{ Cooling tower specifications } \\
\hline & unit & value & & unit & value \\
\hline Nominal capacity & MW & 1.00 & Nominal Capacity & MW & 1.00 \\
\hline Outlet set point & deg. C & 28 & Sump volume & $\mathrm{m}^{3}$ & 4.00 \\
\hline Inlet set point & deg. C & 31 & Design air flow & $\mathrm{m}^{3} / \mathrm{h}$ & 100000 \\
\hline Design ambient temperature & deg. C & 25 & Natural air flow & $\mathrm{m}^{3} / \mathrm{h}$ & 20000 \\
\hline Design fluid flow rate & $\mathrm{kg} / \mathrm{h}$ & 286000 & Design water flow rate & $\mathrm{kg} / \mathrm{h}$ & 120000 \\
\hline Design air flow rate & $\mathrm{kg} / \mathrm{h}$ & 2100000 & Design inlet water temp & deg. C & 35 \\
\hline
\end{tabular}


The use of underground water for cooling purposes is an effective method to reject the waste heat from cooling systems and to increase chiller efficiencies. The heat rejection system is based on a water-to-water heat exchanger coupled with the cooling chiller circuit. The groundwater/shallow water is pumped by a supply well and must be reintroduced in the ground by a return well to avoid the consumption of the resource. In this way a fully renewable rejection method is achieved, and the only environmental constraint is on the weak heating of the reinjected water $\left(5-10^{\circ} \mathrm{C}\right)$.

The geological information are very important in order to understand the type of the water present in the subsoil [23,24] and the in-house Trnsys model includes the geological stratifications, based on the information reported in the specialized literature $[25,26]$. The main parameters that assess the effectiveness of the groundwater heat rejection systems are the average depth of the aquifer and the water temperature and its spatial variation. In the Abu Dhabi region the water table depth progressively increases from the coast to a depth of more than $120 \mathrm{~m}$ but in the considered area a depth close to $50 \mathrm{~m}$ is observed. As the depth increases, the groundwater surface level moves into soil layers with less hydraulic conductivity and the water drainage becomes even more difficult. The water temperature drawn from the wells is around $25 \mathrm{deg}$., but it is enough to move the well by a few kilometers to rise the average temperature to about 30-32 deg. $\mathrm{C}$, as underlined by Alsharhan et al. [27]. The groundwater resources in Riyadh Regions are feed by Jubalia Limestone aquifer [28]. The depth range of the aquifer is estimated from 20 to $200 \mathrm{~m}$ and the permeability is good. The water is not directly suitable for human use but usually employed for livestock and agricultural.

A Trnsys macro have been developed to evaluate the behaviour of a supply well, starting from a mathematical model of the groundwater field. The Trnsys macro includes an Excel type that evaluate the water table level and the well flows, using a Visual Basic Application (VBA) macro. The VBA macro also provides the solution of the ground heat exchange equation with a quasistatic assumption, ensuring a computational speed sufficient for the transient simulation. The ground and well parameters, the input imposed by the simulation in the Trnsys deck and VBA outputs are listed in the left part of Table 6 . The model allows to the user to define the number of soil layers and 10 horizontal regions are provided. The wells are supposed located out of the undisturbed radius, avoiding any mutual interference.

The model has been validated with the experimental data of a step drawdown test performed in 2010. The parameters of a real case were setting in the model and, after the simulation, comparing the characteristic curves. In the reference case all the fundamental parameters and soil characteristics are known. The real and simulated characteristic curve show a good consistency with a maximum overestimation of $(+6 \%)$. A detailed description of the VBA macro, including the mathematical evaluation and validation, are reported in [29].

The geothermal boreholes are vertical loop of pipes where the water is flowing, and the ground is used as heat sink. The numerical model of the heat exchange, developed in VBA, includes the characterization of the field temperature and the borehole. The ground is discretized by a finite number of vertical regions with variable thickness and user defined soil properties. Each vertical region is divided into several horizontal concentric regions where the temperature is considered constant. Subsoil parameters may vary between vertical layers but not between horizontal regions. In addition, a yearly fluctuation of the temperature of the undisturbed soil is considered in according to the available literature. The VBA model, solving the quasi-static equations of the thermal flow in each horizontal region, directly interact with the Trnsys interface: the timevarying input from the Trnsys and output of the two models are available in real time for all the components. Parameters, inputs and outputs are listed in Table 6 (right part). The model has been validated against the Trnsys default model of the boreholes under the same operation condition. A detailed description of the model and the validation is reported in [29]. 
TABLE 6. Water table model and ground heat exchanger model parameters

\begin{tabular}{|c|c|c|c|c|c|}
\hline \multicolumn{3}{|c|}{ Groundwater table and Well Model } & \multicolumn{3}{|c|}{ Ground Heat Exchanger Model } \\
\hline INPUT & Symbol & Unit & INPUT & Symbol & Unit \\
\hline Time & $\mathrm{t}$ & $\mathrm{h}$ & Time & $\mathrm{t}$ & $\mathrm{h}$ \\
\hline Water temperature & T1 & deg. $\mathrm{C}$ & Water temperature & $\mathrm{T} 1$ & deg. $\mathrm{C}$ \\
\hline Heat rejection flowrate & MFR & $\mathrm{kg} / \mathrm{s}$ & Water flowrate & MFR & $\mathrm{kg} / \mathrm{s}$ \\
\hline PARAMETER & Symbol & Unit & PARAMETER & Symbol & Unit \\
\hline Timestep & ts & $\mathrm{h}$ & Timestep & ts & $\mathrm{h}$ \\
\hline Well number & $\mathrm{BN}$ & $\mathrm{N}$ & Borehole number & $\mathrm{BN}$ & $\mathrm{N}$ \\
\hline Well diameter & Dw & $\mathrm{m}$ & Layer thickness & $\mathrm{L}$ & $\mathrm{m}$ \\
\hline Max water table level drop & $\Delta_{\max }$ & $\mathrm{m}$ & Thermal Conductivity & $\lambda$ & $\mathrm{W} / \mathrm{mK}$ \\
\hline Layer thickness & $\mathrm{L}$ & $\mathrm{m}$ & Layer thermal capacity & $\mathrm{Cp}$ & $\mathrm{MJ} / \mathrm{m}^{3} \mathrm{~K}$ \\
\hline Water level $(\mathrm{t}=0)$ & $\mathrm{H}$ & $\mathrm{m}$ & Soil density & $\rho$ & $\mathrm{kg} / \mathrm{m}^{3}$ \\
\hline Hydraulic conductivity* & $\mathrm{k}$ & $\mathrm{m} / \mathrm{s}$ & OUTPUT & Symbol & Unit \\
\hline Water density & $\rho$ & $\mathrm{Kg} / \mathrm{m}^{3}$ & Outlet temperature & $\mathrm{T} 2$ & deg. C \\
\hline Specific yield & $\mathrm{e}$ & $\mathrm{m}^{3} / \mathrm{m}^{3}$ & Heat Rejection Power & HR & $\mathrm{kW}$ \\
\hline OUTPUT & Symbol & Unit & & & \\
\hline Outlet water temp & $\mathrm{T} 2$ & deg. $\mathrm{C}$ & & & \\
\hline Water flowrate & MFR & $\mathrm{kg} / \mathrm{s}$ & & & \\
\hline Weel undisturbed radius & Rind & $\mathrm{m}$ & & & \\
\hline
\end{tabular}

*Transmissivity for Aquiclude $\left(\mathrm{m}^{2} / \mathrm{s}\right)$

\subsection{Optimization}

A multivariable optimization of each configuration of the solar cooling plant has been performed with the aim of minimize the budget cost (objective function) under the constrain of a minimum solar fraction (70\%) [30]. The optimization is achieved using the software GenOpt coupled with Trnsys. To provide a consistent identification of local and global minimum point of the objective function, a two-step process is adopted based on the Particle Swarm (first step) coupled with Hooke-Jeeves algorithm (second step). The objective function, reported in Eq 3, includes the main budget cost of the plants, listed in Tab. 7, reported in the open literature or provided by the manufacturer [31,32]. The considered optimization parameters and constraints are shown in Tab. 8. The cost of the groundwater heat exchanger, according the evaluation of a drilling company, is computed by multiplying the wellbore cost $(40 \mathrm{USD} / \mathrm{m})$ counted twice (supply and return wells) plus a fixed cost of 1100 USD.

$$
\begin{gathered}
f_{\text {min }}=A_{\text {Col }} \cdot \text { Cost }_{\text {Col }}+\operatorname{Cap}_{\text {Abs }} \cdot \text { Cost }_{\text {Abs }}+\operatorname{Vol}_{\text {tank }} \cdot \text { Cost }_{\text {tank }} \\
+N_{H R S} \cdot \text { Cost }_{H R S}+\text { Penalty }_{(S F<0.70)}
\end{gathered}
$$


TABLE 7. Budget costs

\begin{tabular}{|c|c|c|c|c|c|}
\hline \multicolumn{4}{|c|}{ Collectors \& Storage } & \multicolumn{3}{c|}{ Heat Rejection Systems } \\
\hline Parabolic Trough Collectors & USD $/ \mathrm{m}^{2}$ & 280 & Dry cooler & USD/MW & 85000 \\
\hline Chilled Water Tank & USD $/ \mathrm{m}^{3}$ & 425 & Cooling Tower & USD/MW & 71000 \\
\hline Pressurized Hot Water Tank & USD $/ \mathrm{m}^{3}$ & 790 & $\begin{array}{c}\text { Groundwater Heat } \\
\text { Exchanger }\end{array}$ & USD/m & $\begin{array}{c}40(\mathrm{x} 2) \\
+1100\end{array}$ \\
\hline \multicolumn{2}{|c|}{ Chiller } & & Ground Heat Exchanger & USD/m & 50 \\
\hline 2s Absorption Chiller & USD $/ \mathrm{kW}$ & 510 & \multicolumn{3}{c|}{ Single Unit } \\
\hline Aux Compression Chiller & USD $/ \mathrm{kW}$ & 100 & Chiller/Heat Pump & USD /kW & 1200 \\
\hline
\end{tabular}

TABLE 8. Optimization variables (starting value - minimum value - maximum value - step)

\begin{tabular}{|c|c|c|c|}
\hline Collectors Area & & Abu Dhabi & Riyadh \\
\hline Collectors area & $\mathrm{m}^{2}$ & $200-100-300-10$ & $150-60-200-10$ \\
\hline Hot Storage & $\mathrm{m}^{3}$ & $650-400-2000-100$ & $650-100-1000-100$ \\
\hline Heat rejection systems & $\mathrm{kW}$ & $3000-1000-10000-200$ & $1500-500-6000-100$ \\
\hline Rated capacity (fixed) & $\mathrm{kW}$ & 1360 & 860 \\
\hline
\end{tabular}

\section{Results and Discussion}

\subsection{Optimization results}

The optimization process determines the solar field aperture, the capacity of the tank for a fixed rated capacity and the capacity of the four heat rejection system analyzed. The optimization results in terms of aperture area and storage volume (hot and cold) are reported in Fig. 3 for the two locations considered. A notable result is the low solar fraction achieved by the cooling plants coupled with dry cooler ( 0.63 in Abu Dhabi and 0.54 in Riyadh, highlighted by the red bar over the charts) due to the maximum operating temperature of the chiller, indeed the ambient temperature is greater than $35 \mathrm{deg}$. $\mathrm{C}$ for more than $30 \%$ of the time and no the increment in tank capacity or the solar field area allows to ensure the selected solar fraction. The chart shows a solar field reduction for the layout based on the groundwater heat rejection system due to the reliability of the cooling circuit; whilst, the storage tank is similar for the four option except for the plant based on dry cooler. A detailed comparison allows to underline the role of the air humidity in the performance of the cooling tower.

The optimized parameters of the heat rejection system are reported in Tab. 9. The nominal capacity of the dry cooler (AC) and of the vertical ground heat exchange (GB) are much higher than the peak of the heat rejected (3.3 MW in Abu Dhabi and 2.1 MW in Riyadh respectively). Nevertheless, the vertical ground heat exchanger is affected by thermal saturation of soil with a detrimental impact on the heat rejection capability of the system: a very high number of boreholes, with a quite higher total capacity, must be used. In dry region the cooling tower perform better than ground heat exchanger whilst, in humid location, the cooling tower shows a reduced efficiency. 


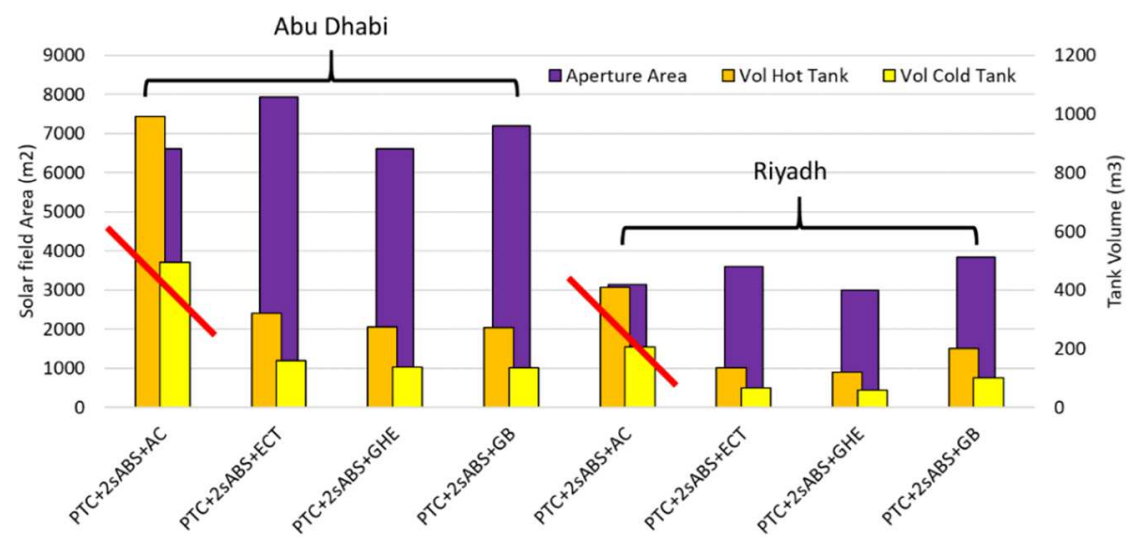

FIGURE 3. Optimization results

TABLE 9. Heat rejection systems optimization results, numerosity and nominal capacity (MW)

\begin{tabular}{|c|c|c|c|}
\hline & number (MW) & Abu Dhabi & Riyadh \\
\hline AC & N (MW) & $8(8)$ & $3.5(3.5)$ \\
\hline ECT & N (MW) & $3(3)$ & $1(1)$ \\
\hline GHE & N (MW) & $36(2.2)$ & $55(1.2)$ \\
\hline GB & N (MW) & $800(4)$ & $340(1.7)$ \\
\hline
\end{tabular}

\subsection{Solar cooling system performance}

A detailed three-daily simulation results are reported for the plant based on AC and GHE, as example of two selected layout, in Fig. 4 (respectively (a) and (b)). The charts show the trend of the main parameters in a typical summer operation in Abu Dhabi, when the cooling load is higher, and the ambient condition are the worst. The light-blue line (chiller production) underlines the different efficiency of the groundwater heat exchanger with respect to the dry cooler. Absorption chiller coupled with dry cooler stop the operation during the high temperature sunny hours whilst groundwater performs very well during the whole day highlighted by the small operation of the auxiliary chiller (violet line).

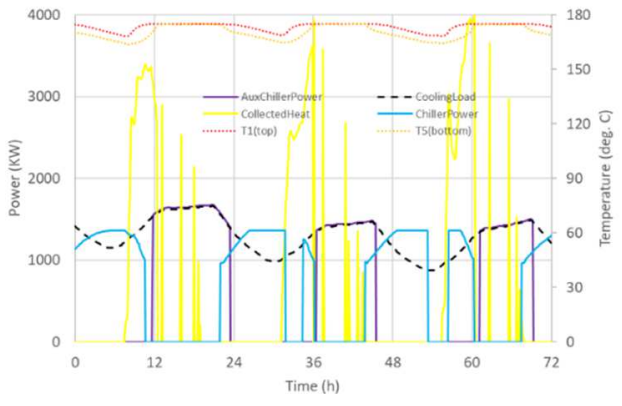

(a) Dry cooler-based plant

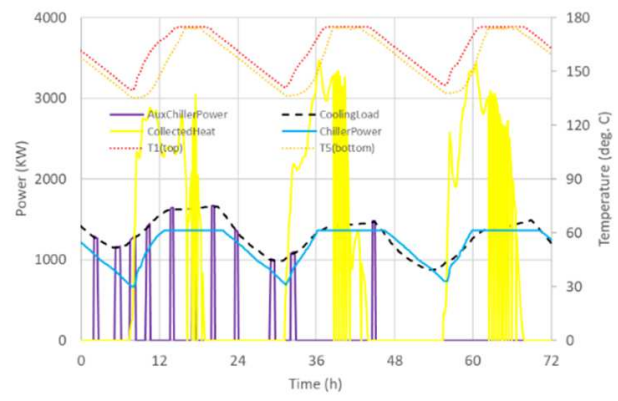

(b) Groundwater heat exchanger-based plant

FIGURE 4. Solar cooling plant simulation in summer days based on AC (a) and GHE (b) (PTC + 2sABS, Abu Dhabi) 
The performed heat rejection systems comparison includes the electric consumption evaluation. The electric consumption comprises the demand for the operation of the absorption chiller, the solar field circulation pump, the compression chiller and the district network. Furthermore, the consumption of the pumping station of the district system has been evaluated using a quasi-static approach, according to the methodology proposed in [17]. The results of the electric consumption evaluation, reported in Fig 5, show the high level of reduction, due to the solar cooling systems adoption, close to $80 \%$ except for the dry cooler (-64\%). The groundwater heat rejection system represents the best solution in terms of electric consumption reduction $(-83.4 \%)$. Furthermore, the water consumption of the cooling tower ( $16258 \mathrm{~m}^{3} / \mathrm{y}$ in Abu Dhabi and $9553 \mathrm{~m}^{3} / \mathrm{y}$ in Riyadh) coupled with the water scarcity of the region impose the adoption of a different solution in order to avoid a consistent depletion of the water resource.

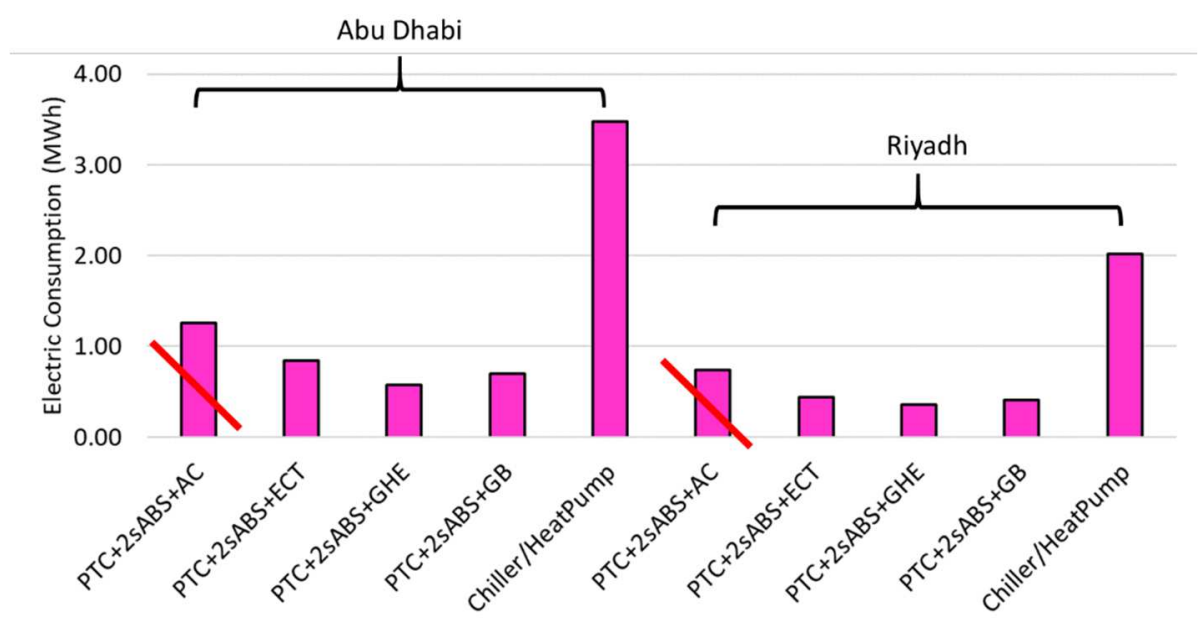

FIGURE 5. Global electric consumption

\subsection{Economic consideration}

Finally, an economic-based comparison has been performed. The budget cost of the optimal solutions is reported in Fig. 6 with special attention to the cost allocation for each component. The district solar cooling plants cost are compared with a standard solution based on the single unit heat pump. The cost, starting from the optimal combination achieved, includes the cost of the district network and the cost of the auxiliary compression chiller (with the same capacity of the absorption one). The adoption of efficient and cost-effective heat rejection system, as groundwater heat exchanger or cooling tower, allows to achieve a similar installation cost to the standard solution; furthermore, the solar district cooling improving the efficiency and the reliability of the cooling delivering. Ground heat exchanger represent an exception: the efficiency of the system, coupled with the low environmental impact, collides with the economic aspect due to the high drilling and equipment costs. The air cooler could represent a competitive solution however the cooling production is not guaranteed.

The bar chart highlights the high economic impact of the solar field that represent half of the total plant cost. Despite the higher budget cost, the better efficiency of the groundwater heat rejection than the cooling tower, especially in humid conditions, allows to reduce the capacity of the components limiting the installation cost. 


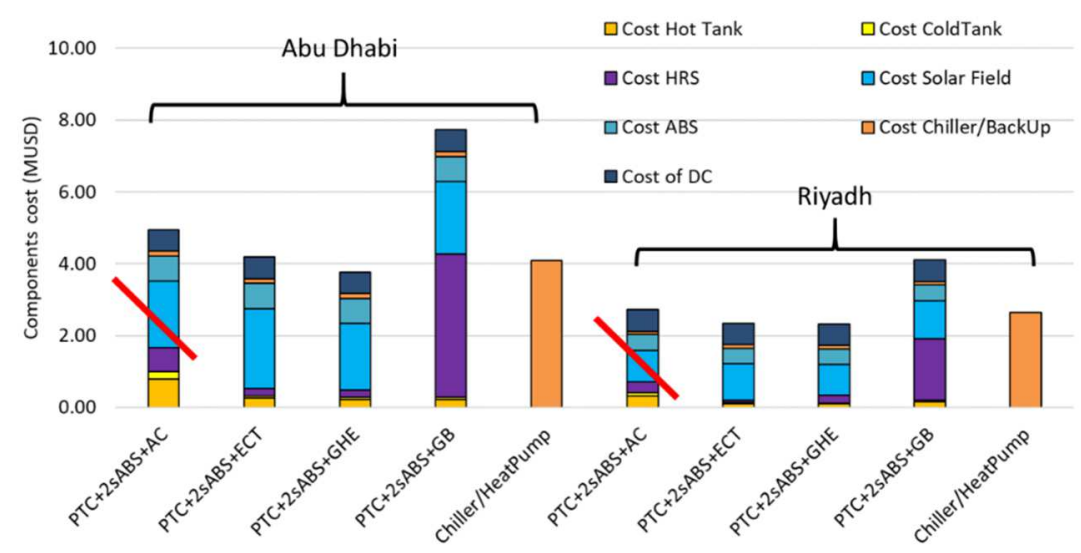

FIGURE 6. Solar district cooling components costs

\section{Conclusions}

The paper presents the performance assessment of a solar district cooling system with special attention to the heat rejection process. The work starts from the modelling of a complete residential compound and the related district network located in in the Gulf region: under Riyadh (warm and dry) and Abu Dhabi (warm and humid) climate conditions. The solar cooling plant is based in a two-stage $\mathrm{Li}$-Br absorption chillers coupled with parabolic trough solar collectors. Four different types of heat rejection systems are considered: Air Cooling (AC), Evaporative Cooling Tower (ECT), Groundwater Heat Exchanger (GHE) and Geothermal Boreholes (GB). The model of the GHE and GB are based on accurate hydrogeological characteristics of the Arabian Peninsula to evaluate the performance of absorption chillers integrated with performance maps provided by the manufacturers.

A complete optimization of the minimum installation cost of cooling plants are carried out and the under the constraint of a 70\% annual solar fraction. The reported results show the major effect of the heat rejection system: the plant based on the air cooler does not achieve the selected solar fraction (63\% in Abu Dhabi and 54\% in Riyadh).

The best option resulted to be the one based on absorption chillers coupled with Groundwater Heat Exchanger in both locations. The annual power consumption is reduced by $84 \%$ in $\mathrm{Abu}$ Dhabi and $82 \%$ in Riyadh compared to conventional cooling systems. The ground heat exchanger and the evaporative cooling tower exhibits a good efficiency in both locations. Unfortunately, environmental issues, as water scarcity, limit the cooling tower operation in dry climates and the high relative humidity force the systems to adopt bigger heat rejection systems in humid climates.

The Ground heat exchanger, despite the efficiency, show a unit cost double of standard solution with lower profitability of the investment.

\section{References}

1. V. Eveloy and D. S. Ayou, Energies 12, (2019)

2. N. Perez-Mora, F. Bava, M. Andersen, C. Bales, G. Lennermo, C. Nielsen, S. Furbo, and V. Martínez-Moll, Int. J. Energy Res. 42, 1419 (2018)

3. H. Lund, B. Möller, B. V. Mathiesen, and A. Dyrelund, Energy 35, 1381 (2010)

4. L. A. Chidambaram, A. S. Ramana, G. Kamaraj, and R. Velraj, Renew. Sustain. Energy Rev. 15, 3220 (2011) 
5. M. Sameti and F. Haghighat, Energy Build. 140, 121 (2017)

6. A. L. S. Chan, V. I. Hanby, and T. T. Chow, Energy Convers. Manag. 48, 2622 (2007)

7. U. Eicker, D. Pietruschka, and R. Pesch, Int. J. Refrig. 35, 729 (2012)

8. D. S. Kim and C. A. Infante Ferreira, Energy Convers. Manag. 50, 1018 (2009)

9. J. Muye, D. S. Ayou, R. Saravanan, and A. Coronas, Appl. Therm. Eng. 97, 59 (2016)

10. T. L. McLing, R. P. Smith, R. W. Smith, D. D. Blackwell, R. C. Roback, and A. J. Sondrup, J. Volcanol. Geotherm. Res. 320, 144 (2016)

11. UN-ESCWA and BGR, INVENTORY OF SHARED WATER RESOURCES IN WESTERN ASIA - Umm Er Radhuma- Dammam Aquifer System (Centre ) (Beirut, 2013)

12. A. A. Murad and R. V. Krishnamurthy, J. Hydrol. 286, 227 (2004)

13. T. B. M. J. Ouarda, C. Charron, K. Niranjan Kumar, P. R. Marpu, H. Ghedira, A. Molini, and I. Khayal, J. Hydrol. 514, 258 (2014)

14. S. Schulz, M. Walther, N. Michelsen, R. Rausch, H. Dirks, M. Al-Saud, R. Merz, O. Kolditz, and C. Schüth, Adv. Water Resour. 103, 32 (2017)

15. D. G. Jorgensen and W. Yasin al-Tikiriti, Glob. Planet. Change 35, 37 (2003)

16. A. Salem and H. E. M. Hashim, Latest Trends Sustain. Green Dev. 105 (2012)

17. G. Franchini, G. Brumana, and A. Perdichizzi, Energy Convers. Manag. 166, 372 (2018)

18. G. Brumana, G. Franchini, and E. Ghirardi, AIP Conf. Proc. 2191, (2019)

19. J. Remund, S. Müller, S. Kunz, and C. Schilter, Meteonorm Handbook Part II: Theory (2012)

20. D. Municipality, G. of Dubai, and D. E. \&Water Authority, Green Building Regulation and Specification (n.d.)

21. ASHRAE, Fundamentals Handbook, S.I. Ameri (1997)

22. Z. Li, L. Liu, and J. Liu, Appl. Therm. Eng. 96, 481 (2016)

23. A. S. Alsharhan, J. Pet. Geol. 12, 253 (1989)

24. S. Macklin, R. Ellison, J. Manning, A. Farrant, and L. Lorenti, Bull. Eng. Geol. Environ. 71, 1 (2012)

25. R. W. Powers, L. F. Ramirez, C. D. Redmond, and E. L. J. Elberg, U.S. Geol. Surv. Prof. Pap. 560-D, 154 (1966)

26. P. R. Johnson, Open \pm File Rep. USGS $\pm \mathrm{OF} \pm 97 \pm 3$. Saudi Arab. Deputy Minist. Miner. Resour. 3, (1998)

27. A. S. Alsharhan, Z. A. Rizk, A. E. M. Nairn, D. W. Bakhit, and S. A. Alhajari, Hydrogeology of an Arid Region - The Arabian Gulf and Adjoining Areas (2001)

28. M. T. Hessein, M. M. Al Yousif, and H. S. Awad, Int. J. Geosci. 3, 71 (2012)

29. G. Brumana, Solar Cooling Technologies and Off-Grid Building Design in Hot Climatic Conditions, University of Bergamo, 2018

30. M. Wetter, Proc. IBPSA’s Build. Simul. 2001 Conf. August 13-15, 2001 Rio Janeiro 9 (2001)

31. IEA-ETSAP and IRENA, Thermal Energy Storage-Technology Brief E17 (2013)

32. P. A. Sørensen, J. E. Nielsen, R. Battisti, T. Schmidt, and D. Trier, Solar District Heating Guidelines (2012) 